\title{
Addressing conflicts of interest in the research paper: a societal demand in contemporary science?
}

\author{
S.M.R. Vasconcelos ${ }^{1}$, M.C. Cassimiro² ${ }^{2}$ M.F.M. Martins ${ }^{3}$ and M. Palácios ${ }^{4}$ \\ ${ }^{1}$ Programa de Educação, Gestão e Difusão em Biociências, Instituto de Bioquímica Médica Leopoldo de Meis, \\ Universidade Federal de Rio de Janeiro, Rio de Janeiro, RJ, Brasil \\ ${ }^{2}$ Fundação Oswaldo Cruz/Instituto Oswaldo Cruz, Rio de Janeiro, RJ, Brasil \\ ${ }^{3}$ Fundação Oswaldo Cruz/Instituto de Comunicação e Informação Tecnológica em Saúde, Rio de Janeiro, RJ, Brasil \\ ${ }^{4}$ Instituto de Estudos em Saúde Coletiva, Universidade Federal do Rio de Janeiro, Rio de Janeiro, RJ, Brasil
}

\begin{abstract}
In the last decade, dialogue between science and society has found a forum in an increasing number of publications on topics such as public engagement with science and public trust in science. Concerning the latter, issues that include cases of research misconduct, accountability in research, and conflicts of interest (COIs) have shaped global discussions on the communication of science. In the publication setting, the perception that hiding COls and/or not managing them well may affect public trust in the research record has grown among editors. We conducted a search for editorials addressing COls between 1989 and 2011, using four major databases: Medline/PubMed, Embase, Scopus, and Web of Knowledge. We explored the content of these editorials and the relationship they established between COls and the public trust in science. Our results demonstrate that the relationship between disclosure of COls and public trust in science has become a major concern among editors. We, thus, argue that COls should be discussed more openly and frequently in graduate courses in the sciences, around the globe, not only in biomedical but also in non-biomedical areas. This is a critical issue in contemporary science, as graduate students are the future voices and decision-makers of the research community. Therefore, COls, especially in the broader context of science and society, merit closer attention from policymakers, researchers, and educators. At times of great expectations for public engagement with science, mishandling of COls may have undesirable consequences for public engagement with science and confidence in the scientific endeavor.
\end{abstract}

Key words: Conflicts of interest; Contemporary science; Science policy; Science education; Research integrity; Science and society

\section{Introduction}

In the last decade, dialogue between science and society has been intense and was echoed in an increasing number of publications focusing on diverse topics such as public engagement with science, public understanding of science, and public trust in science. Concerning the latter, issues that include cases of research misconduct, accountability in research, and conflicts of interest (COIs) have shaped global discussions about the communication of science (1-3). The issue of COls is a case in point. The relationship between disclosure of these conflicts and public trust in research results led the National Institutes of Health (NIH) in 2011 to "tighten conflict-of-interest oversight and to preserve public trust in the face of growing relationships between academia and industry..." (4). At a press briefing, NIH director Francis Collins said "We are confident that the results will further add to the public sense of confidence in the scientific process and the results that come out of $\mathrm{NIH}$-funded research" (4).

In the realm of publications, COls in research papers have been noted as a growing concern, especially since the 1980s (5). Among journal editors, the perception has grown that hiding COIs and/or not managing them well may affect trust among peers and trust of the public in the research record. In 2004, Dr. Drummond Rennie, deputy editor of the Journal of the American Medical Association, stated that "...doctors do not know what papers they can trust in the journals, and the public does not know what to believe" (6). In order to tackle this problem, the declaration

Correspondence: S.M.R. Vasconcelos, Programa de Educação, Gestão e Difusão em Biociências (PEGeD/IBqM/UFRJ), 21941-590 Rio de Janeiro, RJ, Brasil. E-mail: svasconcelos@bioqmed.ufrj.br 
of COls has become a requirement for authors of most international biomedical journals, and many have followed the guidelines published by the International Committee of Medical Journal Editors (7).

In the last few years, however, there seems to be a trend toward requiring declaration of COls for many nonbiomedical journals as well.

The growing affiliation of non-biomedical journals, such as those published by Elsevier and Oxford University Press to the Committee on Publication Ethics, can illustrate this trend (8). These publishers include several non-biomedical journals whose editorial guidelines are gradually changing. Part of these changes suggests a cultural clash when it comes to $\mathrm{COI}$ policies for publication of research papers. For instance, on the website of Elsevier, which publishes around 1250 journals in science, engineering, and other technology fields, one now finds that "all authors should disclose in their manuscript any financial or other substantive conflict of interest that might be construed to influence the results or interpretation of their manuscript" and that "all sources of financial support for the project should be disclosed" (9). According to the Ethical Guidelines for Publication of Chemical Research (revised in 2012) by the American Chemical Society, "conflicts of interest and sources of funding of the research reported must be clearly stated at the time of manuscript submission..." and "the corresponding author must reveal to the editor and to the readers of the journal any potential and/or relevant competing financial or other interest (of all authors) that might be affected by publication of the results..." (10).

Yet, one cannot assume that these guidelines will be adopted readily by novice authors in engineering journals, for example. Internalizing the importance of these guidelines may take much time for different types of research communities. Particularly in the last two decades, we have witnessed a subtle change in the way scientific results are communicated, although the basic format of the research paper has kept its original format, i.e., the Introduction, Methods, Results, and Discussion (IMRAD). Adopted widely in the second half of the 20th century by most scientific fields, this format has undergone only minor changes such as combined sections or inclusion of supplementary material or explanatory notes.

This somewhat stable format can be associated with the fact that the IMRAD continues to reflect on the scientific method, but this is not the sole reason. For many decades, the research community "functioned through a number of well-established practices such as peer review, respect for priority of discovery, comprehensive citation of the literature, meritocratic preferment on the basis of research performance, and so on" (11). From a Mertonian perspective, these would be the norms constituting the scientific ethos (12). The ethos of science tells us that issues such as trust and transparency between authors and reviewers can be taken for granted. This ethos also implies that certain rules in this social interaction can be left unsaid or unwritten. In fact, the following has been widely assumed: "...an incredibly high level of trust in the integrity of scientific discovery and a reliance on the ethical attitudes of individual investigators" (13). But, as Feldman (13) described, "the playing field changed" in the 1980 s, as academic science and industry started to come closer together.

Increasingly, contemporary science has described the rules of the game in writing and also asked that the roles of each player be defined in black and white. In this scenario, instead of assuming, for example, that the classical sentence "The submission of a manuscript implies that it has not been submitted or is under consideration elsewhere" would be taken as a given, many journals require that this and other "specific 'integrity insurance' steps" be declared by authors $(14,15)$. Currently, the trend for many international journals is to require that each author of a manuscript declare what his/her contributions are. Also, many international journals, instead of assuming that the data in the results section are the sole product of the work described in the materials and methods section, now require that the raw data be presented (16). This requirement would allow results in the manuscript to be double-checked.

In 2001, an editorial in the New England Journal of Medicine (NEJM) that mentioned a revision of the Uniform Requirements for Submitted Manuscripts to Biomedical Journals declared that "many of us (in NEJM) will ask the responsible author to sign a statement indicating that he or she accepts full responsibility for the conduct of the trial, had access to the data, and controlled the decision to publish" (17). Today, these requirements seem to be a trend for publication in biomedical and also in nonbiomedical journals $(10,18)$. As already suggested, these requirements can be associated with growing concerns about the issue of trust in contemporary science (19). On the one hand, we may assume that the "publish or perish" environment per se may send the wrong message to authors, and academic journals have to reduce the risk of publishing sloppy and unreliable research results. On the other hand, awareness that both financial and nonfinancial COls may considerably distort research data has grown in the last few years.

In this scientific communication environment, the international discussion on research integrity and the responsible conduct of research (RI/RCR) has played a crucial role. In addition to causing subtle changes in the modus operandi of publishing, reporting, and reviewing research, the discussion on RI/RCR can also be seen as influencing requirements for institutional training programs on research ethics/integrity for young scientists. In many of these programs, mostly in biomedical fields, addressing COls is part of the agenda. This current attention to competing interests in the conduct of research 
seems to be part of today's zeitgeist. In contemporary science, not only financial but also non-financial COls have been assumed as potential sources of bias that might threaten the objectivity associated with or desired in science. Gradually, concerns about disclosure of COls may be noted in disciplinary fields in which these conflicts have not traditionally been addressed as a relevant topic (18). The discussion of these conflicts in climate science, for example, is a case in point (20).

In our view, among the reasons that may explain this closer attention to COls are societal demands for more transparency in the doing and publishing of research. This is true when we consider that public demonstrations of concern in some particular research areas have been attributed to, among other factors, distrust in science and not to lack of scientific knowledge, as commonly claimed (21). In the realm of publications, the investigation of how science and society issues are noted in the approach of journal editors to COls may shed some light on the editors' perceptions of the impact of COls on public confidence in science. To our knowledge, this particular landscape, seen through the eyes of journal editors, has not been explored in the literature. We looked at these societal aspects through the eyes of journal editors because they, together with reviewers, have historically been acknowledged as the gatekeepers of science. They can be regarded as representatives of the scientific community, and their work can have considerable impact on research trends and public policy.

\section{Data Collection}

\section{Search strategy in Medline/PubMed, Embase,} Scopus, and Web of Knowledge

We conducted a search for editorials covering the period between January 1989 and August 2011, using four major databases: Medline/PubMed, Embase, Scopus, and Web of Knowledge. The key words/phrases used for searching in each database are not restricted to financial COls, as can be noted, and many are available in the list of medical subject headings (MeSH, National Library of Medicine) (22). The general strategy was as follows: [(COI or "conflict of interest" or "conflicts of interest" or "conflicts of interests" or conflict-of-interest or disclosure* or "interest policies" or bias) and ("financial ties" or "financial influence" or "financial interest" or "financial association" or investment* or "financial conflicts" or "funding source" or "competing interest" or "dual interest" or "financial relationship" or fund)].

This search strategy was based on that used by Blum et al. (23), although we did not use exactly the same key words/phrases they used for their study, and we did not explore academic genres other than editorials.

In our search, we found 119 documents in Medline, 58 in Embase, 82 in Scopus, and 122 in the Web of Knowledge (Table 1).
Table 1. Distribution of editorials in the four databases (January 1989-August 2011).

\begin{tabular}{lc}
\hline Databases & Documents \\
\hline Medline (PubMed) & 119 \\
Embase & 58 \\
Scopus & 82 \\
Web of Knowledge & 122 \\
\hline
\end{tabular}

From a total of 381 titles, 66 were excluded from our analysis because they appeared in more than one database. However, in the remaining 315 titles, we identified 5 that were repeated or overlapped among 27 different journals (Figure 1). For example, the editorial entitled "Sponsorship, authorship and accountability" by Davidoff et al. (17) appeared in eight different journals. These "same-title" editorials were not excluded from the remaining 315 documents, because we believe they reveal shared views on COls among the 27 different journals that published them.

We went through each one of these 315 documents to confirm whether they were all editorials or included other pieces such as articles, commentaries, or letters. This step was important because we found that not all documents indexed as editorials were really editorials, which could distort our analysis. We found that 140 documents met our inclusion criteria: the document should be accessible through our institutions, so that we could read the entire material, and it should be an "editorial" addressing COls. These publications comprised $44 \%$ of the original sample (315). The remaining

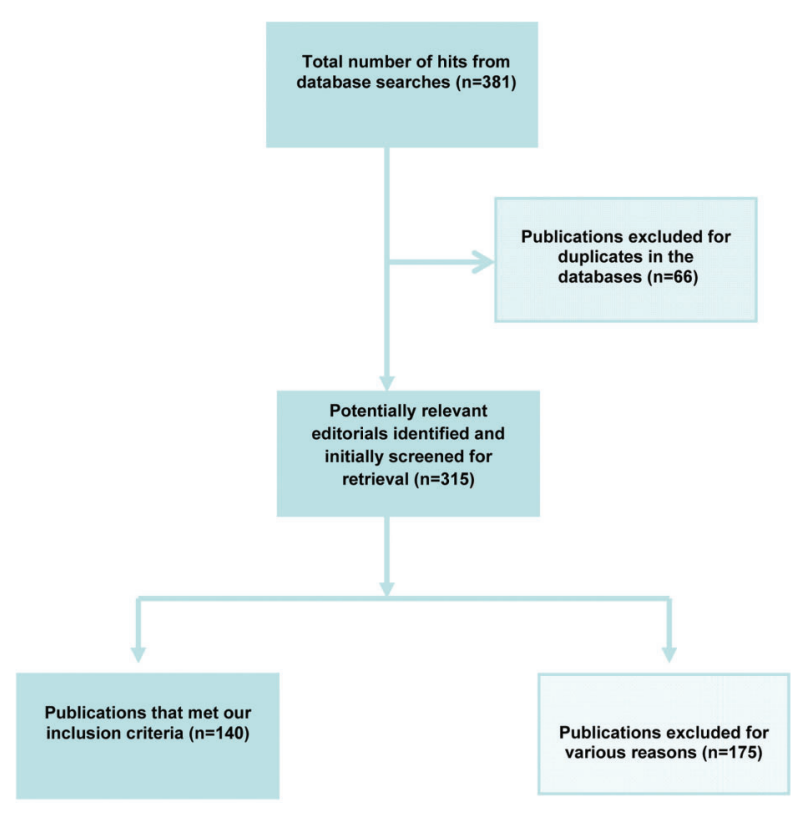

Figure 1. Screening process for the analysis. 
$175(55 \%)$ documents included two categories of publications: i) publications that either did not discuss COls or were not accessible, which we categorized as miscellaneous or non-accessible publications (108); and ii) publications that addressed the issue but were not editorials, although some were indexed as such. These documents included 19 articles, 4 letters, 25 commentaries, 8 discussion pieces, 2 interviews, 1 news, 1 essay, and 7 viewpoints.

For the 140 documents that met our inclusion criteria, we tried to identify those that related COls to the idea of public confidence and trust in researchers and/or science at large as well as credibility of research results. We, thus, searched for "confidence", "trust", and "credibility" in each one of the 140 documents.

\section{Results and Discussion}

We found 48 (34\%) editorials with at least one of the three terms in the text in context we considered relevant to this discussion. A few others containing one of the terms, in phrases (e.g., "confidence interval") or contexts unrelated to the discussion, were not included. We explored the content of these 48 editorials and, in the following section, we show excerpts taken from a sample of these documents. The list of these 48 editorials is available as Supplementary Material.

Among the 48 documents, we found an interesting relationship between the idea of disclosure of COls and that of public confidence and trust in research results in this publication arena, especially in the last few years. In fact, the issue of COls gained more visibility in editorials published by the end of the 1990s in these four databases, with a marked increase at the beginning of the 21st century (Figure 2).

This growth noted in Figure 2 is likely to be associated with concerns over COls that naturally emerged from the increasing academia-industry relationship, which was reinforced especially from the 1980s in North American science, with the Bayh-Dole Act (24). This legislation was a congressional effort to promote "cooperative activities among academia, small business, and industry leading to new products and processes for the marketplace" (25). As expected, this arena had an impact on the editorial realm and gained momentum at the end of the 1990s, when attention to the role of journal editors in addressing COls in publications started to increase. According to Davidoff et al. (26), accountability and independence are closely linked to scientific authorship. As an editor, he declared that the journal would "not review or publish articles based on studies that are conducted under conditions that allow the sponsor to have sole control of the data or to withhold publication."

Attention to COls at that time was also being broadened as cases of misconduct and questionable research practices were increasingly discussed in print. In fact, COls have received particular attention not only from editors but also from institutions, funding agencies, and international conferences (27). Many of these discussions focus on declaring COls as a means to improve reliability of the research record and increase public confidence in science. This relationship was identified through the voice of journal editors in our sample.

\section{Looking at editors' views on COls in the context of science and society}

One of the major issues raised through the voice of editors is that today's research community is more vulnerable to criticism from society when it comes to credibility of results from research with undisclosed COls. The following excerpts illustrate this feature: "In the current climate of media hype and public mistrust, it is particularly important to offer transparency...being exposed as someone who failed to disclose a competing financial interest is a clear invitation to suspicion" (18). "Recently, the popular media has criticized medical journals for not disclosing

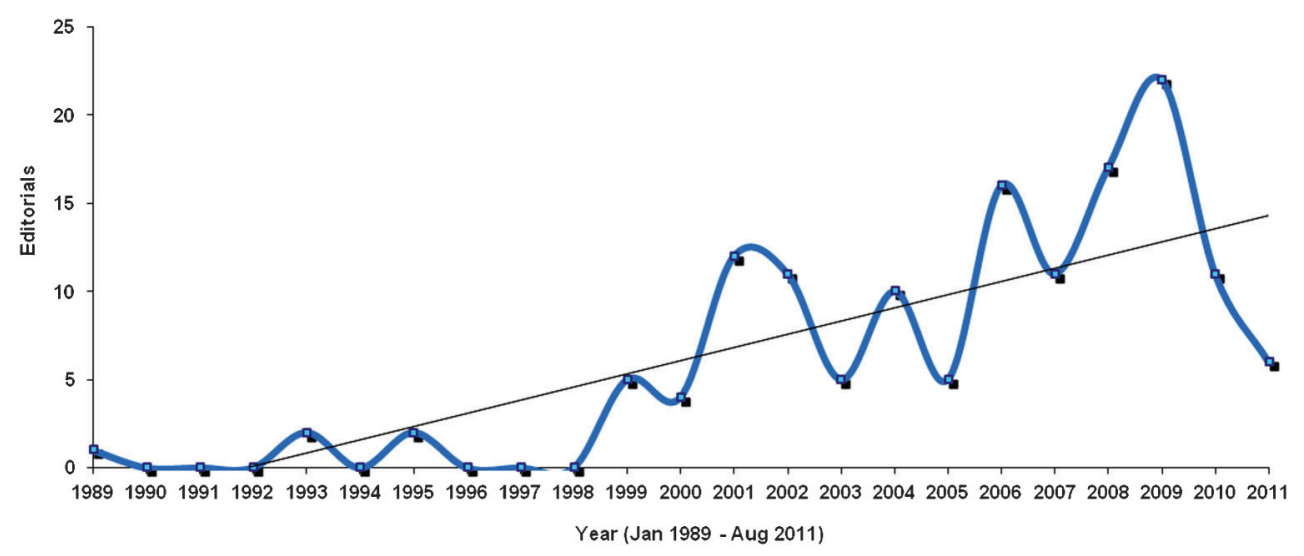

Figure 2. Editorials on conflicts of interest-related issues (Medline, Embase, Scopus, and Web of Science), January 1989-August 2011. 
conflicts of interest..." (28). "Responding to the public outcries, prestigious journals instituted new policies for authors, and AMCs [American Medical Colleges] undertook efforts to mitigate the problem" (13).

Concerning public trust, some of the views expressed in the editorials in our sample are that public confidence in science is at risk or has been eroded and should be regained. Accordingly, some editors reinforced the idea that addressing COls has a role in building public confidence in contemporary science. The following statements illustrate these points: "We have work to do if we are to win back that most precious of all commodities, public trust.... The rules of scientific review and approval of protocols, free of conflict of interest, must be adhered to by our institutions" (29). "... (COIs) cannot be totally eliminated in the modern reality so we have to deal with them. No less than the confidence of our patients and the public at large is at risk if we do not. Evidence of our failure to respond fully and in a timely manner to the recognition of this growing problem is hard to ignore" (30). "The need for transparency in reporting the financial conflicts of interest of authors and the relationships between investigators and funding sources has never been greater and is essential to help maintain confidence and trust in the scientific integrity of medical research articles" (31). " ... One might properly ask what the public thinks about disclosure since, after all, the purpose is to 'ensure the public trust"' (32).

Concerning the public perception of science as a trustworthy enterprise, undisclosed COls may have a detrimental effect, as these editors point out: "'For Science's Gatekeepers, a Credibility Gap', 'ToughTalking Journal Editor Faces Accusations of Leniency', 'Some Seek to Lift Veil on Research Funding'. If such titles of recent newspaper clippings are any indication, public perception of the scientific publishing industry, perhaps still somewhat tender from bruises inflicted earlier this year by stories of fabricated data in a few high-profile articles, has taken another beating" (33).

"...Some authors are not getting the message regarding disclosure reporting requirements and, with these amounts of money involved, the medical establishment and public can easily lose trust in what journals report..." (34). "Trust in the clinical research enterprise is a fragile commodity. Failure to preserve and protect it can easily lead to disruption and losses that may never be fully regained... We all must work to preserve and protect this public trust, and this will happen only if we make it our priority. Conflict of interest or conflict of priorities?" (35).

This analysis of COls in editorials indexed in Medline, Embase, Scopus, and Web of Science suggests, on the one hand, that competing interests in research are frequently associated with biased results and/or the idea of public trust in science. In fact, researchers, science educators, and policymakers have echoed journal editors' concerns over COls that may compromise the credibility of the research record. As remarked by the National Academies, "the level of trust that has characterized science and its relationship with society has contributed to a period of unparalleled scientific productivity. But this trust will endure only if the scientific community devotes itself to exemplifying and transmitting the values associated with ethical scientific conduct" (36).

\section{Concluding Remarks}

The editorials in our sample suggest that public perception about the credibility of research results deserves greater attention among scientists. This is particularly important when we consider that not only biomedical research but many non-biomedical research areas are now being funded by industry. According to recent data on research and development (R\&D) for the countries within the Organization for Economic Cooperation and Development, spending on R\&D by industry in these countries increased from $52 \%$ in 1981 to $65 \%$ in 2008 . According to these data, R\&D spending by foreign investors in countries grew from about US $\$ 30$ billion to US\$67 billion, from 1993 to 2002 (37). This situation may involve more frequent problems linked to undisclosed COls or even to disclosed COls that may not be adequately managed. It is well documented that this changing research climate has already had an impact on public confidence in science, which seems to be weaker for industry-related scientific research (21). This issue suggests that addressing COls could play a fundamental part in efforts to reduce distorted research records, such as those that may be influenced by corporate bias (38) but be taken as sound data by peers and eventually by the public.

In this context, our results point to a broader picture when it comes to disclosure of COls in research papers. Today, undeclared competing interests might add to the reasons justifying the retraction of a paper, and greater exposure of such interests is expected on the part of authors, reviewers, and editors themselves. Concerning authors, Frank Gannon (39) notes, "we (authors) could be more transparent by indicating any conflicts of interest... transparency seems to be a first step to overcome society's distrust in science and scientists". Apart from financial interests, personal, intellectual, and other kinds of competing interests have also been noted as a concern in research papers (40).

We find that the relationship these editorials establish between disclosure of competing interests and credibility of research results corroborates the idea that addressing COls in the research paper is a legitimate societal demand for contemporary science. If so, as the gatekeepers of science, editors are expected to help broaden the attention to COls in publications and the impact these conflicts may have on public confidence in the research community. This is true even if we consider that simple 
disclosure of COls is an adequate response; nevertheless, the question of managing them so that the research record is not distorted seems to be a more severe challenge.

This challenge is of considerable importance for the academic and professional careers of young researchers, who have to face a growing number of competing demands in today's research environment. Dealing successfully with COls is an additional concern and should be more openly and frequently discussed in graduate courses all over the globe, not only in biomedical but also in non-biomedical research areas. On the one hand, these young researchers experience an academic environment that increasingly fosters creativity, innovation, and entrepreneurship. On the other hand, they have to meet a number of ethical challenges such as plagiarism, ghostwriting, honorary authorship, and selective or biased reporting of research results, to name just a few of those that may be associated with COls. In this complex environment, informing the public adequately about science, its processes, achievements, and controversies seems to be another challenge. Today's graduate students, who are "future spokespeople and decisionmakers at science institutions" (21), cannot rely on tacit knowledge to succeed in this environment. They "should be taught about the social and political context of science and how to communicate with the media and a diversity of publics". If this aspect of training is not adequately

\section{References}

1. Bosch X. Safeguarding good scientific practice in Europe. EMBO Rep 2010; 11: 252-257, doi: 10.1038/embor. 2010.32 .

2. Krimsky S, Rothenberg LS. Conflict of interest policies in science and medical journals: editorial practices and author disclosures. Sci Eng Ethics 2001; 7: 205-218, doi: 10.1007/ s11948-001-0041-7.

3. Kreutzberg GW. Scientists and the marketplace of opinions. Scientific credibility takes on a different meaning when reaching out to the public. EMBO Rep 2005; 6: 393-396, doi: 10.1038/sj.embor.7400405.

4. Ledford $\mathrm{H}$. NIH finalizes conflict-of-interest rules. Nature News 2011; Aug 23, doi: 10.1038/news.2011.499.

5. Lundberg GD, Flanagin A. New requirements for authors: signed statements of authorship responsibility and financial disclosure. JAMA 1989; 262: 2003-2004, doi: 10.1001/ jama.1989.03430140121037.

6. Brownlee S. Doctors Without Borders. Washington Monthly Apr 2004. http://www.washingtonmonthly.com/features/ 2004/0404. brownlee.html.

7. International Committee of Medical Journal Editors. Uniform requirements for manuscripts submitted to biomedical journals: updated October 2005. http://www.icmje.org.

8. Committee on Publication Ethics (COPE). http://publication ethics.org/members.

9. Elsevier. Ethical guideline for journal publication. http:// www.elsevier.com/wps/find/authorsview.authors/rights. addressed, this type of public engagement may become "too conflated with marketing and public relations" (21).

Finally, science communicators, policymakers, and educators should reinforce the importance of this topic among all members of the science communication chain, including researchers themselves, journalists, educators, and policymakers. At times of great expectations for public engagement with science, mishandling of COIs can be a serious handicap for the whole research community and may have undesirable consequences for public engagement with and confidence in science.

\section{Supplementary Material}

Click here to view [pdf]

\section{Acknowledgments}

We thank Dr. Jane Robbins, McGuire Center for Enterpreneurship, University of Arizona; Dr. Nicholas Steneck, Research Ethics/Integrity Program, University of Michigan; Dr. Martha Sorenson, Instituto de Bioquímica Médica, UFRJ, and Murilo Vilaça, Research Ethics Committee of Instituto Nacional do Cancer (CEP/INCA), for critical and relevant comments on the manuscript. We also thank Dr. Braulio Santos, Instituto Nacional de Cardiologia (INC), for helping us with methodological aspects of the study and with reviewing part of the data.

10. The American Chemical Society. Ethical Guidelines to Publication of Chemical Research. http://pubs.acs.org/userimages/ ContentEditor/1218054468605/ethics.pdf.

11. Ziman JM. Why must scientists become more ethically sensitive than they used to be? Science 1998; 282: 18131814, doi: 10.1126/science.282.5395.1813.

12. Merton RK. Science and the social order. Phil Sci 1938; 5: 321-337, doi: 10.1086/286513.

13. Feldman AM. Re-envisioning our approach to research in academia. Clin Transl Sci 2008; 1: 181-182, doi: 10.1111/ j.1752-8062.2008.00064.x.

14. Authorship policies. Nature 2009; 458: 1078, doi: 10.1038/ 4581078a.

15. Institute of Electrical and Electronics Engineering (IEEE). Author information page on originality of content. http:// www.ieee.org/publications_standards/publications/rights/ author_originality.html

16. International Council for Scientific and Technical Information. ICSTI Winter Workshop 2012: Delivering Data in Science. http://www.iucr.org/resources/data/meetingreports/icsti-wm-2012.

17. Davidoff F, DeAngelis CD, Drazen JM, Hoey J, Højgaard L, Horton R, et al. Sponsorship, authorship, and accountability. $N$ Engl J Med 2001; 345: 825-827, doi: 10.1056/ NEJMed20010093.

18. Nothing to declare? Nat Methods 2006; 3: 869, doi: 10. 1038/nmeth1106-869. 
19. Sztompka P. Trust in science: Robert Merton's inspirations. J Classical Sociol 2007; 7: 211-220, doi: 10.1177/1468795X 07078038.

20. Kahan D. Why we are poles apart on climate change. Nature 2012; 488: 255, doi: 10.1038/488255a.

21. Bubela $T$, Nisbet MC, Borchelt R, Brunger F, Critchley $C$, Einsiedel $\mathrm{E}$, et al. Science communication reconsidered. Nat Biotechnol 2009; 27: 514-518, doi: 10.1038/nbt0609-514.

22. Medical subject headings (MeSH). http://www.nlm.nih.gov/ mesh.

23. Blum JA, Freeman K, Dart RC, Cooper RJ. Requirements and definitions in conflict of interest policies of medical journals. JAMA 2009; 302: 2230-2234, doi: 10.1001/jama. 2009.1669.

24. Bekelman JE, Li Y, Gross CP. Scope and impact of financial conflicts of interest in biomedical research: a systematic review. JAMA 2003; 289: 454-465, doi: 10.1001/jama. 289.4.454.

25. Schacht $\mathrm{WH}$. The Bayh-Dole act: selected issues in patent policy and the commercialization of technology. Congressional research service. http://www.ieeeusa.org/ policy/eyeonwashington/2011/documents/bayh.pdf.

26. Davidoff F, DeAngelis CD, Drazen JM, Nicholls MG, Hoey J, Hojgaard L, et al. Sponsorship, authorship and accountability. Med J Aust 2001; 175: 294-296.

27. Mayer T, Steneck N. Final report to ESF and ORI. First World Conference on Research Integrity: Fostering responsible research. 2007 Sep 16-19; Lisbon. http://www.icsu.org/ freedom-responsibility/pdf-images/WCRI_2007_report.pdf.

28. Barr DB. Integrity in science. J Expo Sci Environ Epidemiol 2007; 17: 123, doi: 10.1038/sj.jes.7500573.

29. Chabner BA. The trust factor. Oncologist 2002; 7: 94-95, doi: 10.1634/theoncologist.7-2-94.

30. Wyse DG. Conflict of interest-draining the swamp means confronting alligators. J Interv Card Electrophysiol 2005; 13 : 5-7, doi: 10.1007/s10840-005-0987-5

31. Fontanarosa PB, Flanagin A, DeAngelis CD. Reporting conflicts of interest, financial aspects of research, and role of sponsors in funded studies. JAMA 2005; 294: 110-111, doi: 10.1001/jama.294.1.110.

32. Johnson DH, Horn L. Authorship and industry financial relationships: the tie that binds. J Clin Oncol 2010; 28: 12811283, doi: 10.1200/JCO.2009.26.9753.

33. A matter of trust. Nature Immunol 2006; 7: 1005, doi: 10.1038/ni1006-1005

34. Liesegang TJ, Schachat AP. Enhanced reporting of potential conflicts of interest: rationale and new form. Am J Ophthalmol 2011; 151: 391-393, doi: 10.1016/j.ajo.2010. 12.001.

35. Nabel EG. Conflict of interest - or conflict of priorities? $N$ Engl J Med 2006; 355: 2365-2367, doi: 10.1056/ NEJMe068238.

36. The National Academies. On being a scientist: responsible conduct in research. 2nd edn. Washington: The National Academies Press; 1995

37. International Council for Science. ICSU foresight analysis. http://www.icsu.org/publications/reports-and-reviews/icsuforesight-analysis/download-report-1.

38. Fuchs FD. The corporate bias and the molding of prescription practices: the case of hypertension. Braz J Med Biol Res 2009; 42: 224-228, doi: 10.1590/S0100-879X2009 000300002.

39. Gannon F. Money in scientists' pockets. EMBO Rep 2001; 2: 75, doi: 10.1093/embo-reports/kve030.

40. Young SY. Bias in the research literature and conflict of interest: an issue for publishers, editors, reviewers and authors, and it is not just about the money. J Psychiatry Neurosci 2009; 34: 412-417. 